\title{
European Perspectives on Recent Tonal Theories, Their Models, and Analytical Tools *
}

\author{
Christophe Guillotel-Nothmann
}

NOTE: The examples for the (text-only) PDF version of this item are available online at: http://www.mtosmt.org/issues/mto.18.24.4/mto.18.24.4.guillotel-nothmann.php

KEYWORDS: analytical tools, theoretical models, directional tendency of chord progressions, centricity, hierarchical articulation of tonal syntax

ABSTRACT: The articles collected here were part of a one-day thematic session held during the 7 th European Music Analysis Conference (Leuven, Belgium, September 17-20, 2014). The session was dedicated to current understandings of tonality, particularly recent European perspectives and their connections to historical theory. Despite differences in methods and aims, the contributions here engage in dialogue by identifying specific research traditions and approaches - ranging from hermeneutical philosophy to neostructuralism - and by addressing characteristics of tonality. Three main threads run throughout: (1) the directional tendency of chord progressions; (2) centricity; and (3) hierarchical organization. Together, the perspectives adopted suggest that progress in the understanding of tonal language depends on a continuing dialectic between the theoretical discourse of the past and modern tools and models-including analysis of large corpora.

DOI: $10.30535 / \mathrm{mto} .24 .4 .9$

Received April 2016

Volume 24, Number 4, December 2018

Copyright $(0) 2018$ Society for Music Theory

[1] The contributions collected here were originally presented during a one-day thematic session at the 7th European Music Analysis Conference held in Leuven, Belgium from September 17-20, 2014. That session was dedicated to the current understanding of tonality, considered from analytical and theoretical points of view.

[2] Thomas Christensen (2016a) draws attention to the fact that the question of tonality, the focus of musicological research half a century ago, has lost most of its significance today. If the passionate debates about tonality have faded, the understanding of tonality as a system and as a historical phenomenon nevertheless remains topical. The tabula rasa announced by dodecaphonism and the Darmstadt school in the mid-twentieth century was not realized, and the linguistic imperialism of tonality has not lost its influence, either in art music or in popular repertoires. The questions that seemed critical in the artistic and political context of the post-war years-when was the birth of tonality? In what geographical sphere? And in which cultural context? - produced answers and spurred evolution in investigative techniques that opened new fields of research. Among these are the structural organization of pretonal corpora and their relation to common practice; the 
identification of tonal coherence in the repertoires at the other end of the historical continuum, which are situated a priori outside tonality; and the historical theorization of writing techniques and the significance of this for our current understanding of tonality.

[3] The contributors who gathered during this conference held a common interest in tonality as an essential construction of Western music. If tonality seems unquestionable and if it is considered by some scholars as "the only habitable planet discovered so far" (Tymoczko 2011, 393), it nevertheless seems pointless to attempt agreement on even a general definition. The reasons for this paradoxical situation are numerous. First among them is the mutability of tonality, considered not only from a historical perspective but also from an achronic point of view. Tonality is neither a static construction nor is it confined to the musical substance itself; rather, it is an immaterial construction that rebuilds in each synchronic stratum and each individual work.

[4] Another issue in investigating tonality is its dual nature as a system on the synchronic level but as the result of a non-uniform historical process on the diachronic level. Identifying the system and the process requires different scientific methodologies that are difficult to combine and incorporate into a coherent epistemological framework (Polth 2016).

[5] In addition, differing conceptions of tonality arise from the distinct aspects that are examined according to individual aims: analyzing large-scale evolutionary processes or individual works, understanding what composers do or how music is perceived, teaching and composing, or theorizing in order to grasp deep structure and meaning. The aim of the session at Leuven was neither to agree on what tonality is nor to identify the most accurate model, but rather to contribute to the current state of knowledge by comparing different theoretical and analytical points of view. Thus, the articles gathered in this issue rely on different disciplines, ranging from mathematics to history and philosophy. They make use of various epistemological approaches encompassing statistics and hermeneutics, and they adopt different methodological perspectives, from large-scale statistical analysis to close reading of individual pieces.

[6] An earlier international conference at King's College London in 2008 helped participants gain analytical, historical, and cultural perspectives on how we might understand tonality. ${ }^{(1)}$ The following year, a symposium in Tours emphasized the trans-historical dimension of tonality and scrutinized musical repertoires and theoretical constructions from the Middle Ages to the contemporary period. ${ }^{(2)}$

[7] The session in Leuven continued this reflection by focusing on recent tonal theories and analytical models. The initial call for papers invited submissions on the following question: "What can recent analytical tools and theoretical constructions with analytical implications tell us about how we understand tonality?" The talks were intended to give an overview of the different approaches that had partly been presented at previous conferences but had substantially evolved in recent years. In addition, the session aimed at identifying the characteristic features of tonality that crystallize through the different ways tonal music, in a broad sense, is analyzed and theorized today. This self-reflexive approach, deducing tonal characteristics from the underpinnings of contemporary theories and analytical tools, implied a historical perspective as well: it was intended to show how a dialectic between modern theories and theoretical constructions of the past might enrich contemporary models and our current understanding of tonality.

[8] The remainder of this introduction summarizes and categorizes the insights on tonality emerging from the methodological traditions, analytical tools, and theoretical models adopted in the individual articles. As a whole, this special issue of MTO does not claim to give an ordered and exhaustive picture of tonality. It restricts itself to presenting a panel of theoretical and analytical approaches whose varied perspectives reflect our current understanding of tonality and, in some cases, its relation to historical models.

\section{European traditions and their distinctions}

[9] Unlike the London symposium in 2008, where North American papers dominated, European researchers were strongly represented in Tours and at the session in Leuven. ${ }^{(3)}$ French papers 
outweighed the others in Tours in 2009, but the Leuven session in 2014 offered a diversified panel bringing together researchers from British, Dutch, French, German, North American, and Spanish institutions. ${ }^{(4)}$ The presentations, the ensuing discussions, and the roundtable organized at the end of the session highlighted the diversity of traditions and approaches that characterize research on tonality today. At the same time, they drew attention to differences in the research traditions on the subject. While true for research on tonality within Europe, this applies especially to the transatlantic musicological dialogue. If American research is not sufficiently taken into account by European musicology, the reverse seems at least equally true: research currently conducted in Europe on the history and the organization of tonality is scarcely known in North America. These considerations, along with a decision by the two North American panelists to withdraw their papers from this collection, have fostered the idea of focusing on European perspectives on tonality, its organization, and its history. ${ }^{(5)}$

[10] European musicology is kaleidoscopic in nature and less unified than its North American counterpart. The contributions in this issue do not claim to cover fully and uniformly the multiplicity of research perspectives devoted to the subject on the Old Continent, but they do identify specific research traditions and approaches.

[11] Hans-Georg Gadamer's hermeneutical philosophy (1960) was seminal for German-speaking musicology, including research on tonality. The "poetics of doubt" (Christensen 2016b) cultivated by Dahlhaus (1967) deeply challenged disciplinary certainties. Dahlhaus's approach opened up new avenues of reflection by showing that theoretical positions, whether historical or contemporary, are never neutral but are based on more or less obvious conditions of truth. The systematic questioning of what we think we know about tonality and its theories and the favoring of a potentially endless dialogue on the possible interpretations of the historical and cultural heritage - the musical works and the theoretical writings - are disconcerting and may seem unnecessarily complicated. Still, this general approach, applied in some contributions here, does not restrict itself to highlighting the inconsistencies or weaknesses of previous or contemporary points of view. On the contrary, it takes into account the content of the theorems encountered by reconsidering them and renewing them in the light of our own truth conditions, premises, and dogmatic positions.

[12] Research on tonality is very different in the Francophone context, marked by the historical and comparative approach inspired by literary philology (Chailley 1951) and by the use of quantitative methods for exploring musical language (Gut 1969). It was the proximity with linguistics, structuralism, and semiology, however, that exerted the strongest influence on the theorization of tonality during the last three decades of the twentieth century. Nicolas Ruwet's theory of segmentation (1966), based on repetition and transformation, and the semiological model of Jean Molino (1975), opened new perspectives for investigating the logic and meaning of tonal language. Jean-Jacques Nattiez (1975), Célestin Deliège (1984), and Nicolas Meeùs (1992) refocused research on the exploration of the work's internal structures and significance, drawing attention to the fact that the analysis of musical syntax implies a semiological dimension and showing that intrinsic musical meanings - like the meaning of harmonic units - are essentially context-dependent. The theory of harmonic vectors (Meeùs 2000), to which several articles of this collection refer, is one important result of these currents of thought. ${ }^{(6)}$

[13] The articles in this issue also derive their distinctive character from their particular relation to theoretical sources. The reception of Schenker and his theories in post-war Germany, for example, is very different from the Schenkerian orthodoxy that emerged through the readings and translations of the North American school. The German reception sketched paths that the theory of the fundamental structure could have taken but that were ultimately abandoned in favor of a mainstream musicology (Schwab-Felisch 2005). The situation is again different in France, where Schenker's ideas - virtually unknown until the end of the 1970s - were first presented in an amended version (Deliège 1984) and then introduced by means of a more faithful translation of Der freie Satz (Schenker 1993). This assimilation of Schenker's writings differs from the Anglophone reception by a less unified approach and by different, sometimes closer, relations to the original, and is reflected in this collection through implicit and explicit references to Schenkerian theory. The contributors also explore theories hitherto almost unknown to the international musicological 
community because their sources remain largely inaccessible. This is the case for the first detailed English-language description of the Tonfeldtheorie of Hungarian conductor and theorist Albert Simon.

[14] Finally, some articles gathered here testify to the particular relation of European musicology to neo-Riemannian theory. Although having their roots in Europe, neo-Riemannian tools were designed on North American ground at a particular moment in the history of musicology: when music analysis had to face critics of the Schenkerian postulate that makes tonal unity an essential aesthetic and ideological principle. By abstracting from tonal hierarchies and diatonicity, the transformational approach searched for a formalized and objective methodological answer to the analysis of repertoires that question tonal unity. While sensitive to the initial intentions and potential of neo-Riemannian theory, the research represented in this volume aims also at exploring the possible ways of integrating tools traditionally associated with tonal analysis - harmonic progressions and their relationship to diatonicity - to the transformational approach. Furthermore, the hermeneutical perspective reflects on how the reinterpretation of romantic theory in the light of transformational theory affects the way in which compositional techniques and the work's underlying harmonic structures are understood.

\section{Theoretical models, analytical tools, and tonal characteristics}

[15] The articles that follow testify to a productive diversity. They are the product of eight individual authors partly belonging to different musicological traditions. Despite their differences in methods and aims, they nevertheless interact and engage in dialogue in that they all tackle characteristics of tonality by investigating them from different points of view, be they structural, cognitive, historical, or hermeneutical. Three characteristics especially crystallize through the prism of the theoretical models and analytical tools described: (1) directional tendency of chord progressions; (2) centricity; and (3) hierarchical organization.

[16] These three criteria, which resonate with "three of the most compelling theories ever conceived for modeling . . tonality" (Christensen 2008, 19) - Rameau's fundamental bass, Riemann's harmonic functions, and Schenker's Ursatz-are not equally represented, either in the collection as a whole or in the individual contributions. One of them, in particular - the criterion of centricityoften remains implicit or is discussed though absent in the theoretical models under consideration. These criteria nonetheless constitute main threads running through the different conceptions of tonality represented in the articles.

\subsection{Directional tendency}

[17] Local-level harmonic progressions and their directional tendency - the preferential use of goaldirected cadential root progression up a fourth (or down a fifth), down a third, and up a secondwere among the first characteristics to be examined in the history of tonal theory. They play a decisive role in Rameau's theory of fundamental bass - which, as Nicolas Meeùs (2003) points out, is not about chord inversion, but about chord progression - and they become decisive in Kirnberger's and Sechter's harmonic theories. But what is the status of this criterion in tonality, and how does it evolve from a historical point of view?

[18] The article by Thomas Noll and Karst de Jong addresses this question by stressing the critical role of root progressions for a better understanding of tonality, both diachronically and from the perspective of its underlying cognitive mechanisms. The three tetractic modes, key to the authors' theory, correspond in their prototypical state to the paradigmatic tonal cadences I-IV-V-I, I-II-VI, and I-IV-VII-I. They are complemented by an original minor third substitution theory that involves a mediation between the melodic and harmonic dimensions of musical syntax. This mediation is central to the authors' discussion of the dialogue between "fundamental bass and real bass." Noll and de Jong conclude that, due to their combinatorial properties, these modes constitute an appropriate starting point for the study of tonal harmonic syntax.

[19] Nicolas Meeùs adopts an opposing perspective. He argues against the idea that tonality governs root progressions, instead focusing on how root progressions govern tonality. This 
viewpoint redefines the relationship between tonality and syntax. Harmonic progressions are not the result of tonality, but, on the contrary, they constrain, define, and recreate tonality in each work, contributing to its specific structural and artistic characteristics. The ambition of the theory of harmonic vectors (THV) is to describe tonality without presupposing it and without projecting it on the work analyzed. This methodological orientation has proven particularly fruitful for analysis of repertoires outside the common practice era, where tonal coherence is not conditioned in the same way by prototypical cadential progressions.

[20] These repertoires and methodological choices constitute the starting point of the article by Christophe Guillotel-Nothmann on the asymmetry of root progressions, that is, the imbalance between progressions up a fourth, down a third, and up a second on the one hand, and complementary root progressions down a fourth, up a third, and down a second, on the other hand. The study investigates the evolution of syntactic constraints from a diachronic perspective in a large corpus of madrigal cycles published in the period 1530-1638. The results confirm that the status of goal-directed root progressions evolves in time, not only in quantity but also in quality. The preferred root progressions up a fourth, down a third, and up a second are conditioned almost accidentally by counterpoint rules in pretonal polyphony, but those progressions evolve to become a main factor constraining and conditioning tonal harmony. The author argues that the changing status of these goal-directed root progressions is decisive for the crystallization of harmonic tonality, its intrinsic organization, and the way its syntax is understood.

[21] Taking into account harmonic progressions and, in some cases, their directional tendency, has led to a better understanding of the microstructural properties of harmonic syntax. It has shown how these characteristics evolve and has allowed for the deduction of generative rules. Many theories focusing on chord progressions, however, do not take into account hierarchical organization and in some cases ignore centricity. This leads one to ask what the microstructural properties inferred from the chord level can tell us about higher hierarchical levels, and whether it may be possible to strengthen the mediation between directional tendency and centricity in theoretical models.

[22] Meeùs [10] acknowledges that the THV will not provide a satisfactory explanation of tonality "as long as it fails to justify tonal constraints and their relation to the harmonic progressions." To better grasp these constraints, his article examines the interdependency between directional tendency, centricity, and diatonic organization by jointly taking into account pitch classes, chord morphologies, and root progressions. The evolution outlined in works by Lassus, Vulpius, Bach, and Reger suggests that the irregular distribution of roots and the possible shift of diatonic qualia through modulation are decisive constraints that have to be taken into account jointly with directional tendency. The results suggest furthermore that the single criterion of harmony is not always sufficient to accurately identify how tonality crystallizes in a work.

[23] The theory of Noll and de Jong, on the other hand, writes both directed motion and centricity into its very structure, since the tetractic modes derive from the division of the tonal space and represent the simultaneous and successive relations within it. Moreover, by borrowing from Schenker the idea of tonal deployment and by associating the tetractic modes with the middleground, their approach is also sensitive to the hierarchical articulation of tonal syntax. This interdependency, exemplified through an analysis of Scriabin, Etude op. 2, no. 1, also draws attention to the difficulty that faces any general tonal theory in trying to provide truly generative and predictive rewriting rules.

[24] Fundamental bass and neo-Riemannian theory reflect voice leading. Accordingly, there is no need to oppose these two approaches, as they explore different aspects of the same thing. In addition, both perspectives almost necessarily imply a triadic background. This background grants that melodic leaps can always be reduced to parsimonious voice leading through possible register transfers. Given the importance of melodic fluidity for tonality, one must consider the status of the triad and of chord dissonances not only as acoustic phenomena but also as conceptual ones. Under what conditions is it possible to assume harmonic degrees as an abstraction of a triad? Is the criterion of the triad - beyond its importance from a vertical point of view - also relevant to the horizontal succession of harmonies, as Rameau suggests? Finally, neo-Riemannian theories and 
root progression theories help to describe contrapuntal voice leading, but since both imply an abstraction, there is reason to ask whether they constitute conceptually salient criteria, compared (for example) to the real bass.

[25] The article on conditional and spontaneous asymmetry by Guillotel-Nothmann argues that the recognition of chords - whether triads or dissonant sonorities - is a matter of contextual interpretation. In harmonic tonality, the preferred direction of chord progressions - up a fourth, down a third, and up a second - plays a decisive role in the sequencing of harmonic units. This fact leads one to explore the reasons for the changing status of the preferred direction, and attracts attention to the conceptual shift that might have been occasioned by irregular dissonances in the early seventeenth century. The resulting deductions question the universal validity of a number of concepts from traditional tonal theory, especially the distinction between suspension dissonances and chordal dissonances, and they shed new light on the relationship between chord dissonance and the crystallization of tonality.

\subsection{Centricity}

[26] From a historical point of view, the concept of centricity takes shape in the eighteenth century through Marpurg's idea that the tonic is the home of the composition. This perspective was developed by Kirnberger, Vogler, Koch, and Weber, all of whom take as a starting point the chord position in the scale. Riemann's concept of tonality implies analogous phenomena to those of Fétis, but asserts that tonality can be systematically subsumed into three harmonic functions. These functions attest to a static and symmetrical understanding of tonality. They do not focus on the way chords follow each other, but aim at characterizing isolated harmonic units and defining their relation to the tonic. What does the changing status of centricity within models tell us from a hermeneutical point of view about the way tonality is understood and about the aesthetic possibilities available to composers?

[27] Jan Philip Sprick shows that theoretical descriptions of the sequence work metaphorically as seismographs, reflecting the underlying conception of tonality. As such, the status of the phenomenon and its interpretation allows implicit deductions on how tonality is understood.

[28] Historical Partimenti and Satzmodelle, Riemann's Große Kompositionslehre (1903), and contemporary schema theories by Gjerdingen (2007) all discuss the sequence from the perspective of compositional techniques. Accordingly, they understand the phenomenon - and thus tonalityfrom a dynamic perspective, focusing more on the linear succession of events than on their relationship to a tonal center. Theories of tonal functions, on the other hand, often put forward as stereotypical Fétis's conception of the sequence as temporarily suspending tonality (Fétis 1844, 253). By doing so, these constructions grant a critical role to the tonic as a central unifying pole, decisive for understanding both the sequence and tonality. Finally, from a Schenkerian perspective, the sequence is associated with the foreground or the middleground. As such, it contributes to the elaboration of structural degrees and enhances tonal coherence instead of suspending it.

[29] Sprick shows how theoretical assumptions influence the interpretation of a phenomenon whose importance can hardly be overestimated in traditional tonality. The article also reminds us of how longstanding historical conceptions - for example, the functional interpretation of the tonic as a central pole-affect recent models and theoretical constructions, both of the sequence and of tonality. As with the other historically and hermeneutically oriented papers in this collection, the article opens up perspectives for the critical analysis, extension, and renewal of contemporary theory and analysis.

[30] As mentioned earlier, by deriving the tetractic modes from the division of the tonal space and by putting them in relation with Schenkerian middleground patterns, the theory of Noll and de Jong writes centricity into its very structure. But it is probably not a coincidence that centricity often appears in absentia in the theoretical models under consideration in this volume. Meeùs stresses that it is essential to (re-)introduce the concept of tonicization in the THV so that it can provide a satisfactory explanation of tonality. Hugues Seress, on the other hand, proposes an extension of neo-Riemannian tools in order to identify tonal coherence at different structural levels. 
Both the THV and neo-Riemannian tools were developed in reaction to theoretical models focused on the tonic, either considered in relation to other harmonic functions or described from the point of view of its elaboration through different hierarchical levels. By deliberately ignoring centricity, the THV and neo-Riemannian tools have highlighted other, sometimes overlooked phenomena of syntactic coherence, and have extended the scope of analytical investigation to repertoires crossing the borders of tonality. At the same time, they have put aside a criterion formerly considered as essential for tonal coherence. The theoretical approaches in this collection testify to a need to maintain a methodological distance with regard to centricity while developing tools able to grasp and to describe it more accurately in different repertoires and at different structural levels. In doing so, they reflect both the key role of centricity for tonal coherence and its changing status in the history of music and its theories.

\subsection{Hierarchical organization}

[31] The theoretical distinction between deep structure and surface events emerges from rhetorical models and first takes shape in Christoph Bernhard's theories of figures. It is, however, in Schenkerian analysis that the elaboration of the background and its converse, the reduction of the foreground, become key to understanding and theorizing tonality. The tonal theory of Lerdahl and Jackendoff was seminal in transposing Chomskyan transformational grammars to musical articulation. At the same time, their theory fostered the development of more recent models, including those by Martin Rohrmeier, who proposes intrinsically generative rules that can be applied to common practice tonality.

[32] An important contribution of neo-Riemannian theory is that it establishes a direct relationship between the twelve chromatic degrees without mediation through a tonic and without supposing hierarchical organization. This approach is highly effective when it comes to late tonality. At the same time, it leaves out other potentially important tonal characteristics, including centricity and hierarchical articulation. The dialectic between background and foreground shown by Schenker and more recent generative theories remains largely inaccessible to neo-Riemannian theory. These approaches, however, do not necessarily focus exclusively on the voice leading of the foreground. They imply a reduction of elaborations - passing notes, suspensions - leading to a more abstract melodic and harmonic skeleton. This implicit rewriting distinguishes this approach from certain historical voice-leading patterns.

[33] Ariane Jeßulat addresses this issue by equating traditional patterns of voice leading and contemporary models with Renate Lachmann's "diegetic" and "diagrammatic" paradigms. While the former calls for a narrative and interpretive approach, the latter is expected to provide valid, universal models. For Lachmann, both paradigms coexist despite their apparent antagonism, just as both approaches play a role in almost all analytical models. Taking as a point of departure the so-called Weitzmann regions - harmonic contexts implicitly or explicitly involving the augmented triad-Jessulat shows that the nineteenth-century Satzmodelle and modern transformational theories do not imply the same level of abstraction: the former focus almost exclusively on the foreground whereas the latter involve more abstract relations. Through scrutiny of theoretical sources by Weitzmann and Sechter and using examples from Brahms and Schubert as illustrations, the article shows that compositional techniques and their evolution are intrinsically linked to a change in perspective, namely, that chromatic alterations in the foreground become constitutive units and parts of a deeper and more abstract layer of harmony, and thus diatonic dissonant contexts evolve in an expanded chromatic setting. The article draws attention to the fact that in order to analyze this transition, an approach is needed that takes into account both historical patterns of voice leading and tools derived from contemporary transformational theories.

[34] Transformational theories, starting with neo-Riemannian theories, are not transformational in the linguistic sense. They formalize the progression from unit $A$ to unit $B$ on the horizontal axis, without theorizing the rewriting of an element " $\mathrm{A}$ " as two or more units on the vertical axis, thus separating foreground from background.

[35] In his article, Seress addresses the question of tonal hierarchies by considering the articulation between hierarchical layers, with particular attention to the middleground. If transformational 
theories allow one to grasp tonality at macrostructural and microstructural levels, they do not sufficiently take into account the intermediate levels. Seress investigates the relationship between the different layers of tonal organization using concepts of intervallic distance (expressed in terms of tones and semitones), modal orientation (the alternation of the chord's mode), and polarity (sharpward and flatward direction in the cycle of fifths).

[36] Applied to the first movement of Ernő Dohnányi's Piano Quintet op. 26, these criteria confirm that the principles governing tonal syntax strongly differ according to the hierarchical level considered. The analysis highlights a strong polarization at the macrostructural level, one still governed by tonal hierarchies. In this respect, the analysis establishes, at the level of the work taken as a whole, an interesting and rather unexpected link with the directional tendency of chord progressions identified by the THV at the microstructural level. Conversely, the analytical tools developed highlight the importance of major third relationships at the chord level. Thus, they not only question the idea of a systematic recursion of syntactic levels, but they also provide answers where the concept of functional cycle is no longer valid or remains arbitrary. Seress's tools are derived from repertoires situated at the border of tonality. Their future development and application to common practice could possibly lead to a better understanding of the middleground, and to development of rules for its identification and organization.

[37] The Tonfeldtheorie of Albert Simon, as it is described by Bernhard Haas (2004), distinguishes hierarchical layers, but, compared to Schenker, Simon draws on very different assumptions. The theory implies a concept of tonality that is not defined through relation to a tonic but to a pitch field understood as a functional interpretive unit. What is more, Tonfeldtheorie is not sensitive to linear voice leading and gives no particular rule for pitch order in one field. These theoretical positions lead to further questions. What can pitch fields tell us about the qualia of distinct pitches and their particularities in late tonal and early atonal works? How is it possible to suppose a multilayered organization while abstracting away from centricity and specific relations to a tonic? Finally, do Schenker's and Simon's different conceptions of tonal articulation reflect an evolution from one to the other, or simply difference?

[38] Michael Polth's article addresses these issues by probing the criteria relevant for the association of different pitches to the same pitch field and, conversely, for allocating the same pitch to distinct fields. These considerations suggest that, in the absence of voice leading as a prominent conceptual category, sound textures and the "concrete material shaping of a pitch" ([30]) become decisive factors for the conceptual identification of pitch fields in late tonal works. Tonfeldtheorie is particularly suitable for the analysis of hierarchical organization in repertoires where tone color becomes a central feature. The arguments put forward suggest that fundamental differences between Simonian and Schenkerian theory reflect the development of compositional techniques and thus the evolution of tonality at the dawn of the twentieth century.

\section{Conclusion}

[39] The perspectives outlined here at first glance seem to offer a rather heterogeneous picture of tonality. Furthermore, some may be disconcerting in their refusal of a rigorous formalization or because of dialectical positions that seem unnecessarily complicated. These attitudes are, however, inherent parts of the authors' methods and are motivated by the desire to grasp the phenomenon of tonality in all its complexity and to explore conclusions arising from conceptual tensions between the individual theoretical constructions.

[40] Taken as a group, however, the various theoretical perspectives converge and reflect strong characteristics of a complex system, subjected as it has been to important evolutionary pressures on the diachronic level while being variously reinterpreted on the synchronic level.

[41] Increasing access to machine-readable musical sources and the possibility of analyzing data with the tools of the digital humanities will undoubtedly lead in the long term to a better understanding of tonality. Still, quantitative approaches will not always prove sufficient to reconstitute a conceptual background, which is decisive for any analysis that seeks to go beyond a 
literal interpretation of the score and grasp deeper meanings. This is especially true for tonality, as an intangible and conceptual phenomenon.

[42] The articles gathered in this issue suggest that a dialogue between the theoretical discourse of the past and modern tools and models, including analysis of large corpora, is necessary for movement forward in the understanding of tonal language. They show that it is critical today to transcend a rigid opposition between emic and etic approaches. The motto "let analysis proliferate" that Steven Rings (2014) gave to this journey is a great encouragement for efforts to find ways for complementary analytical and theoretical perspectives to coexist. The stakes are high, especially for improving our understanding of repertoires at the border of tonality. We hope that the selfreflexive approach adopted here will be useful for this purpose.

Christophe Guillotel-Nothmann

Institut de Recherche en Musicologie (IReMus - UMR 8223)

2 rue de Louvois

75002 Paris, France

christophe.guillotel-nothmann@cnrs.com

\section{Works Cited}

Chailley, Jacques. 1951. Traité historique d'analyse musicale. Leduc.

Christensen, Thomas, ed. 2008. The Cambridge History of Western Music Theory. Cambridge University Press.

Christensen, Thomas. 2016a. "Die Entstehung der Entstehung." Zeitschrift der Gesellschaft für Musiktheorie, Sonderausgabe. http://www.gmth.de/zeitschrift/artikel/861.aspx.

2016b. "Dahlhaus und die Poetik des Zweifels." Zeitschrift der Gesellschaft für

Musiktheorie, Sonderausgabe. http://www.gmth.de/zeitschrift/artikel/859.aspx.

Deliège, Célestin. 1984. Les Fondements de la musique tonale: une perspective analytique post-schenkerienne. Lattès.

Dahlhaus, Carl. 1967. Untersuchungen über die Entstehung der harmonischen Tonalität. Bärenreiter.

Doğantan-Dack, Mine 2013. “Tonality: The Shape of Affect.” Empirical Musicology Review 8: 208-218. http://emusicology.org/article/view/3943.

Fétis, François-Joseph. 1844. Traité complet de la théorie et de la pratique de l'harmonie. Schlesinger.

Gadamer, Hans-Georg. 1960. Wahrheit und Methode: Grundzüge einer philosophischen Hermeneutik. Mohr.

Gut, Serge. 1969. La tierce harmonique dans la musique occidentale. Heugel.

Gjerdingen, Robert. 2007. Music in the Galant Style. Oxford University Press.

Haas, Bernhard. 2004. Die neue Tonalität von Schubert bis Webern. Hören und Analysieren nach Albert Simon. Noetzel.

Meeùs, Nicolas. 1992. "A propos de logique et de signification musicales." Analyse musicale 28: 57-59.

\footnotetext{
Progressions." Music Theory Online 6.1.

http://www.mtosmt.org/issues/mto.00.6.1/mto.00.6.1.meeus.html.

2003. “Vecteurs harmoniques." Musurgia 10 (3-4), 7-34.
}

2000. "Toward a Post-Schoenbergian Grammar of Tonal and Pre-tonal Harmonic

Molino, Jean. 1975. "Fait musical et sémiologie de la musique." Musique en jeu 17: 37-62. Translated in Jean Molino; J. A. Underwood, Craig Ayrey. 1990. "Musical Fact and the Semiology of Music." 
Nattiez, Jean-Jacques. 1975. Fondements d'une sémiologie de la musique. Union générale d'éditions.

Polth, Michael. 2016. "Tonalität als geschichtliches System >Dogmatische Denkform ‘ und historischer Nachweis." Zeitschrift der Gesellschaft für Musiktheorie, Sonderausgabe.

http://www.gmth.de/zeitschrift/artikel/862.aspx.

Riemann, Hugo. 1903. Große Kompositionslehre, II. Band. Der polyphone Satz. Spemann.

Rings, Steven. 2014. "Transformational Theory and Empirical Research on Tonality." Paper presented at EuroMAC, Leuven, Belgium.

Ruwet, Nicolas. 1966. "Méthodes d'analyse en musicologie." Revue Belge de Musicologie 20. Translated in Nicolas Ruwet; Mark Everist. 1987. "Methods of Analysis in Musicology." Music Analysis 6 (1/2): 3-9, 11-36.

Schenker, Heinrich. (trans. Nicolas Meeùs). 1993. L'Écriture libre, P. Mardaga.

Schwab-Felisch, Oliver. 2005. "Zur Rezeption der Schichtenlehre Heinrich Schenkers in der deutschsprachigen Musikwissenschaft nach 1945." Zeitschrift der Gesellschaft für Musiktheorie 2 (2/3). http://www.gmth.de/zeitschrift/artikel/532.aspx.

Tymoczko, Dmitri. 2011. A Geometry of Music: Harmony and Counterpoint in the Extended Common Practice. Oxford University Press.

2014. "A Study on the Origins of Harmonic Tonality." Paper presented at EuroMAC, Leuven, Belgium.

\section{Footnotes}

* It is my pleasant duty to acknowledge the help this collection has received from MTO's team in the process of reviewing and editing. My special thanks go to David Neumeyer for serving as guest editor of this collection, to the anonymous reviewers and to MTO's main editors Nicole Biamonte and Jeff Perry who shepherded this collection from its initial submission up to its present publication.

Return to text

1. Tonality in Perspective, Daniel Chua (org.), King's College London, March 27-29, 2008.

Return to text

2. Regards actuels sur la tonalité, Henri Gonnard (org.), Université François-Rabelais, Tours, November 26-28, 2009.

Return to text

3. Of the twenty-five papers given in London, $32 \%$ were by researchers from European institutions and $64 \%$ by researchers from North American institutions. Conversely, of the twenty-two and nine papers given respectively in Tours and Leuven, $82 \%$ and $78 \%$ came from European institutions, versus $18 \%$ and $22 \%$ from North American institutions (the other authors came from Asian institutions).

Return to text

4. Fifteen (about 70\%) of the twenty-two papers given in Tours were by researchers from French institutions, the others being from Israel (1), Switzerland (1), Spain (1), and North America (4). The Leuven session, for its part, brought together researchers attached to British (1), Dutch (1), French (3), German (2), North American (2), and Spanish (1) institutions.

Return to text

5. Steven Rings's talk (2014) and Dmitri Tymoczko's (2014) were initially part of this session, which also included a British talk by Mine Doğantan-Dack, entitled “Tonality: An Evolutionary 
Perspective." The key ideas of the latter are published in Doğantan-Dack 2013.

Return to text

6. For a comprehensive bibliography on the THV, see online:

http://nicolas.meeus.free.fr/NMVecteurs.html.

Return to text

\section{Copyright Statement}

Copyright $\odot 2018$ by the Society for Music Theory. All rights reserved.

[1] Copyrights for individual items published in Music Theory Online (MTO) are held by their authors. Items appearing in MTO may be saved and stored in electronic or paper form, and may be shared among individuals for purposes of scholarly research or discussion, but may not be republished in any form, electronic or print, without prior, written permission from the author(s), and advance notification of the editors of MTO.

[2] Any redistributed form of items published in $M T O$ must include the following information in a form appropriate to the medium in which the items are to appear:

This item appeared in Music Theory Online in [VOLUME \#, ISSUE \#] on [DAY/MONTH/YEAR]. It was

authored by [FULL NAME, EMAIL ADDRESS], with whose written permission it is reprinted here.

[3] Libraries may archive issues of MTO in electronic or paper form for public access so long as each issue is stored in its entirety, and no access fee is charged. Exceptions to these requirements must be approved in writing by the editors of MTO, who will act in accordance with the decisions of the Society for Music Theory.

This document and all portions thereof are protected by U.S. and international copyright laws. Material contained herein may be copied and/or distributed for research purposes only. 